\title{
Urodynamics has a future: comment on editorial by Lose and Klarskov
}

\author{
P. E. P. Petros
}

Published online: 17 May 2014

(C) The International Urogynecological Association 2014

\section{Dear Editor,}

I write to support the statement by Lose and Klarskov "There is a need to develop UDS (urodynamics) and reappraisal of its utility in predicting surgical outcome" [1]. The problem is that conventional urodynamic testing is not a good predictor of surgical outcome, as demonstrated by the New England Journal of Medicine study and the 2006 Cochrane statement [2].

An effective predictive test already exists, a urodynamic validation of a simple clinical test described below [3]: pressing upwards on one side of the urethra (so as not to obstruct), immediately behind the pubic bone, controls urine loss and restores urethrovesical geometry, as demonstrated with transperineal ultrasound [4]. In my experience, the test is a good predictor of surgical success for urinary stress incontinence (USI), even for patients with cough-activated detrusor overactivity (DO), which it also controls. The same manoeuvre performed with pressure transducers in place caused increased urethral pressure on coughing [3]. This urodynamic test was found to be a more reliable predictor than transperineal ultrasound in patients with previous Burch operations [3].

This manoeuvre, "simulated" or "virtual" operation, is based on the concept that the directional striated muscle vector forces responsible for active closure (and opening) of the urethral tube rely on firm ligamentous insertion points. Loose ligaments lead to effective lengthening of muscle, which in turn invalidates the muscle forces generated [5], leading to the inability to close the urethra, and therefore, incontinence. Pressing upwards creates a firm anchoring point for the muscle forces, reversing this process.

Fundamental to any predictive test is an understanding of the basic mechanisms of continence. Simplistically, whether a

Related correspondence can be found at doi:10.1007/s00192-014-2403-0 and doi:10.1007/s00192-014-2404-z

P. E. P. Petros $(\bowtie)$

31/93 Elizabeth Bay Road, Elizabeth Bay, NSW 2011, Australia

e-mail: pp@kvinno.com patient leaks or not depends on whether the resistance in the urethral tube at that point in time can resist the opening forces imposed upon it. This resistance is determined by the urethral radius, being inversely proportional to its fifth power at that point in time [6]. The only objective test that has the capacity to measure urethral radius, and therefore, intraurethral resistance, is a highly innovative (but neglected) technique developed by Lose himself [7]. If the Lose apparatus could be calibrated for its radius readings to be expressed as resistance, it would add 3 orders of magnitude (1,000 times) to the predictive accuracy of [4] as pressure reflects only the second power of the radius.

Conflicts of interest None.

\section{References}

1. Lose G, Klarskov N (2014) Utility of invasive urodynamics before surgery for stress urinary incontinence. Int Urogynecol J 25:1-3. doi: 10.1007/s00192-013-2163-2

2. Nager $\mathrm{C}$ et al. (2012) A randomized trial of urodynamic testing before stress-incontinence surgery. N Engl J Med 366:1987-1997. doi:10. 1056/NEJMoa1113595. Accessed 24 May 2012

3. Petros PE, Von Konsky B (1999) Anchoring the midurethra restores bladder neck anatomy and continence. Lancet 354(9193):997-998

4. Petros PE (2003) Changes in bladder neck geometry and closure pressure following midurethral anchoring suggest a musculo-elastic mechanism activates closure. Neurourol Urodyn 22:191-197

5. Gordon AM, Huxley AF, Julian FJ (1966) The variation in isometric tension with sarcomere length in vertebrate muscle fibres. J Physiol 184(1):170-192

6. Bush MB, Petros PEP, Barrett- Lennard BR (1997) On the flow through the human urethra. Biomechanics 30:967-969

7. Lose LG (1992) Simultaneous recording of pressure and crosssectional area in the female urethra: a study of urethral closure function in healthy and stress incontinent women. Neurourol Urodyn 11:55-89 